\title{
CLOSED INTRAMEDULLARY NAILING OF THE TIBIA
}

\author{
D. BAMFORD, D. STANLEY
}

The recommended position of the patient for closed intramedullary nailing of the tibia is with the hip flexed $45^{\circ}$ and the knee flexed $90^{\circ}$. The most commonly advocated method of achieving this requires an orthopaedic table with crossbar attachment. We have found this awkward to set up and inconvenient for image intensification.

We describe a method of positioning the patient which utilises the Watson-Jones frame (1932); this is easy to set up and allows good access for both the surgeon and the radiographer.

Method. The only equipment required is a standard operating table with detachable leg piece, a WatsonJones frame, and a lithotomy stirrup. The patient is initially positioned supine on the full table, and the affected leg prepared around the ankle. A Steinmann pin is inserted through the calcaneum and a loop fastened to the pin. The leg is then elevated and prepared for operation.

The leg section of the operating table is then removed and the segment under the patient's thigh raised so that the hip is flexed to $45^{\circ}$. The Watson-Jones frame is attached to the operating table and the thigh placed in the padded cup of the frame. In this position the whole of the thigh is supported and the knee is flexed at $90^{\circ}$ (Fig. 1). The unaffected leg is placed in a lithotomy stirrup. The Steinmann pin loop is attached to the hook of the Watson-Jones frame. Traction is applied through the frame in order to reduce and hold the fracture. The patient is now in a position to allow the closed tibial nailing to commence.

Discussion. The Watson-Jones frame was designed to allow traction and reduction of tibial fractures, and to hold this position while plaster was applied. The use of the frame for closed tibial nailing has, we believe, several advantages over other methods of positioning the patient (Alms 1962; Merle D'Aubigné et al 1974). The frame is simple to apply and is used in a similar fashion to that

D. Bamford, FRCS, Orthopaedic Registrar

D. Stanley, BSc, FRCS, Orthopaedic Senior Registrar

Orthopaedic Department, Royal Hallamshire Hospital, Glossop Road, Sheffield S10 2JF, England.

Correspondence to Mr D. Stanley.

(C) 1990 British Editorial Society of Bone and Joint Surgery 0301-620X/90/5R83\$2.00

J Bone Joint Surg [Br] 1990; 72-B:926. employed when tibial fractures are manipulated and placed in plaster. By adjusting the operating table, however, the leg is positioned at $45^{\circ}$ to the horizontal rather than the $90^{\circ}$ angle used for plaster application. The technique avoids cumbersome table attachments, and allows free access to both sides of the tibia. In addition, the radiographer is able to obtain an excellent position for the image intensifier since its positioning is unhindered by table legs.

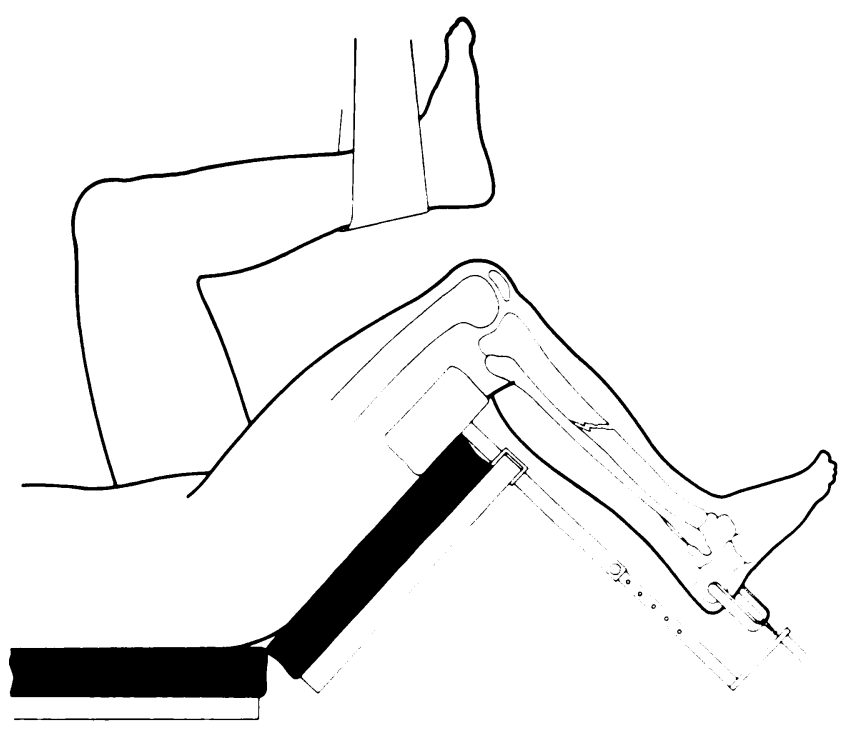

Fig. 1

The only disadvantage that we have found is that the metal bar of the frame prevents a true anteroposterior image of the tibia from being obtained. This can be compensated for by obtaining minimal oblique views, and these, together with a true lateral view seem sufficient.

No benefits in any form have been received or will be received from a commercial party related directly or indirectly to the subject of this article.

\section{REFERENCES}

Alms M. Medullary nailing for fracture of the shaft of the tibia. $J$ Bone Joint Surg [Br] 1962; 44-B:328-39.

Merle d'Aubigné R, Maurer P, Zucman J, Masse Y. Blind intramedullary nailing for tibial fractures. Clin Orthop 1974; $105: 267-75$.

Watson-Jones R. Treatment of fractures of the shafts of the tibia and fibula: a new tibia traction apparatus. J Bone Joint Surg 1932; 14:591-610. 